\title{
A produção científica sobre a comunicação na revista brasileira Interface
}

\section{The scientific production about communication in the Brazilian journal Interface}

Antonio Pithon Cyrinoa, Andrea Langbeckerb, Monica Petraccic, Janine Miranda Cardosod, Ricardo Rodrigues Teixeirae

a Departamento de Saúde Pública, Faculdade de Medicina, Universidade Estadual Paulista, Brasil

$\mathrm{b}$ Instituto de Saúde Coletiva, Universidade Federal da Bahia, Brasil

C Instituto de Investigaciones Gino Germani, Facultad de Ciencias Sociales, Universidad de Buenos Aires, Argentina

d Instituto de Comunicação e Informação Científica e Tecnologia em Saúde, Fundação Oswaldo Cruz, Brasil

e Departamento de Medicina Preventiva, Faculdade de Medicina, Universidade de São Paulo, Brasil

\section{Resumo}

Introdução: Considerando a importância de Interface entre as revistas de Saúde Coletiva e enquanto espaço de produção de saberes e práticas nesse campo na América Latina, este trabalho teve como objetivo mapear a produção científica que investigou a comunicação, em suas diversas dimensões, durante os 20 anos desse periódico (de 1997 a 2017). Metodologia: Trata-se de estudo descritivo dos aspectos quantitativos e qualitativos da produção sobre comunicação mediante análise de conteúdo. Resultados: Nesse período, a revista publicou 1.343 manuscritos. Desse total, 154 manuscritos tiveram a comunicação como um dos seus objetos, o que representou $11,47 \%$ do total de artigos. Predominaram os estudos empíricos (52,60\%), seguidos dos teóricos (25,97\%). Os campos temáticos identificados foram: Mídias (26,62\%); Saúde Coletiva (26,62\%); Formação profissional (16,88\%); Relacionamento profissional, paciente, família e serviço (14,29\%); Tecnologias de Informação e Comunicação (9,09\%); e Comunicação e Sociedade (1,30\%). Conclusão: Essa diversidade temática demonstra a riqueza e heterogeneidade do campo Comunicação e Saúde. Entretanto, o baixo número de publicações relacionadas à comunicação evidencia a escassez da produção científica sobre esse objeto no campo da Saúde Coletiva.

Palavras-chave: comunicação; mídia; Saúde Coletiva; formação profissional; relação profissional-paciente; Tecnologias de Informação e Comunicação.

\begin{abstract}
Introduction: Considering the importance of the Brazilian journal Interface among the Collective Health journals and as a space of production of knowledge and practices in the area in Latin America, this work aimed at mapping the scientific production related to communication in its various dimensions throughout the magazine's 20 years of existence (1997 to 2017). Methodology: This is a descriptive study of the quantitative and qualitative aspects of production on communication through content analysis. Results: During this period, the journal published 1,343 manuscripts among which 154 were related to communication, representing $11.47 \%$ of all papers. Empirical studies were predominant (52.6\%), followed by theoretical studies $(25.97 \%)$. The identified thematic fields were: Media (26.62\%); Collective Health (26.62\%); Professional education (16.88\%); Professional relationship, patient/family/service (14.29\%); Information and Communication Technologies (9.09\%); and Communication and society (1.3\%). Conclusion: This thematic diversity demonstrates the Communication and Health field's wealth and heterogeneity of topics. However, the low number of publications related to communication highlights the lack of scientific production on this matter in Collective Health.
\end{abstract}

Keywords: communication; media; collective health; professional education; professional-patient relationship; Information and Communication Technologies. 


\section{Introdução}

O surgimento da área de Comunicação e Saúde é recente e remonta à segunda metade do século $X X$, sendo formada a partir do encontro dessas duas áreas; e do entrelaçamento dos aspectos sociais e comunicacionais da saúde e, especialmente, para alguns autores, dos aspectos relacionados à Saúde Coletiva (Araújo \& Cardoso, 2007; Petracci, 2012). Tem caráter interdisciplinar e polissêmico. Na América Latina, transita de uma fase de construção (Araújo e Cardoso, 2007; Cuberli, 2008) para a sua consolidação acadêmica.

Enquanto objeto de interesse científico, podese considerar que as pesquisas realizadas, nos Estados Unidos, foram pioneiras na reflexão sobre as particularidades da comunicação relacionadas à saúde. $\mathrm{Na}$ década de 1940, pesquisadores americanos encontraram nos centros de pesquisas interdisciplinares a possibilidade de desenvolver estudos relacionados à comunicação e saúde (Pessoni, 2006). Algumas pesquisas realizadas em Palo Alto, na Califórnia, também ganharam destaque, no fim da década de 1950, ao desenvolverem trabalhos sobre Psiquiatria a partir de uma abordagem comunicativa relacional (Valente, 2011).

Iturrizaga (2011) considera que, a partir da década de 1950/1960, a área transformou-se em um dos setores de destaque nos estudos de comunicação no âmbito anglo-saxônico. Já Rogers (1996) destaca a criação do Stanford Heart Disease Prevention Program, em 1971, como um propulsor que alavancou o processo de crescimento e reconhecimento dessa área de estudos (Rogers, 1996; Pessoni, 2006). A primeira revista acadêmica, a Health Communication, foi lançada em 1989, e a segunda, Journal of Health Communication, em 1996, sendo consideradas marcos importantes para a consolidação dessa área (Iturrizaga, 2011; Bertol, 2012).

No primeiro número dessa revista, o pesquisador norte-americano Everett Rogers apresentou um conceito de comunicação e saúde que se tornou uma referência:

Health communication is a specialty field of communication study that includes the media agenda-setting process for health issues; media advocacy for health; scientific communication among biomedical scientists; doctorpatient communication; and, particularly, the design and evaluation of preventive health communication campaigns" (Roger, 1996, p. 15)
A partir dessa conceitualização, o mapeamento posterior da área da Comunicação e Saúde trouxe visibilidade à heterogeneidade do campo, à luz das mudanças comunicacionais contemporâneas (Cuberli y Araujo, 2015; Waisbord 2015; Rodríguez Zoya, 2017).

No caso brasileiro, foi somente a partir da década de 1990 que começaram a se desenvolver, de forma mais articulada, ações que impulsionaram a produção científica relacionada à comunicação e saúde, como a implementação de cursos de pós-graduação, criação de um grupo de trabalho em Comunicação e Saúde na Associação Brasileira de Saúde Coletiva (Abrasco) e a realização de congressos nessa área (Araújo e Cardoso, 2007; Cardoso e Rocha, 2018).

Nesse contexto, foi lançado, durante o V Congresso Brasileiro de Saúde Coletiva, em 1997, o primeiro fascículo da revista Interface - Comunicação, Saúde, Educação. Não havia, na época, periódico científico no Brasil e na América Latina com esse perfil (Cyrino et al., 2015).

De caráter interdisciplinar, o escopo da publicação versa sobre dois grandes eixos: a comunicação e a educação e sua inter-relação - tomando as palavras da própria revista - "com as práticas de saúde, a formação de profissionais de saúde (universitária e continuada) e a Saúde Coletiva em sua articulação com a Filosofia, as Artes e as Ciências Sociais e Humanas".

Editada pela Universidade Estadual Paulista, campus Botucatu, a Interface privilegia pesquisas qualitativas com abordagens críticas e inovadoras para o campo em questão. A revista publica - em português, inglês e espanhol - textos ensaísticos, analíticos (teóricos ou empíricos), revisões de literatura, entrevistas, relatos de experiências, resenhas e comunicações breves.

É uma das nove revistas latino-americanas voltadas para comunicação que está indexada na base de dados Scopus, contando com um dos melhores índices: quartil Q2 e H5Index 20 (Lotero-Echeverri, 2019). Também se encontra indexada na Emerging Sources Citation Index (incluída na plataforma Web of Science), Scielo e outras bases.

Em uma recente revisão de literatura sobre a comunicação em revistas de Saúde Pública no período 2005-2015, Terrón et al. (2017) destacaram a Interface pelo maior número de artigos sobre comunicação publicados. Na pesquisa - baseada na análise de 18 revistas de Saúde Pública de dez países disponíveis na base de dados Scielo -, constataram que, das 18 revistas analisadas, 12 traziam artigos com esse perfil, 
o que representou $0,62 \%$ (124 artigos sobre um total de 19.866 manuscritos publicados). Apesar do número pouco expressivo de artigos sobre comunicação, 41,12\% (51 artigos) correspondiam à Interface.

Os autores apontaram ainda que a Interface foi a revista que incluiu um maior número de artigos teóricoconceituais, pesquisas com métodos qualitativos e baseadas em técnicas sistemáticas.

Considerando a relevância dessa revista entre as publicações de Saúde Coletiva e enquanto espaço de produção de saberes e práticas nesse campo, este trabalho teve como objetivo mapear a produção científica que investigou a comunicação, em suas diversas dimensões, durante os 20 anos desse periódico (de 1997 a 2017). Acreditamos que, assim, é possível trazer um amplo mapeamento dessa produção, apresentando e refletindo sobre as tendências existentes e as abordagens presentes na área de Comunicação e Saúde na América Latina.

\section{Metodologia}

Trata-se de estudo descritivo dos aspectos quantitativos e qualitativos da produção sobre comunicação mediante análise de conteúdo. Durante o período investigado - de 1997 a 2017 -, a revista publicou 1.343 manuscritos ${ }^{1}$.

Para a construção do corpus empírico, foram descarregados todos os manuscritos da Interface, disponíveis na plataforma Scielo. Para selecionar os artigos que compuseram a análise, foi realizada a leitura dos títulos, resumos e das palavras-chave de todos os manuscritos. No caso de dúvida, realizou-se a leitura do texto completo. Foram selecionados aqueles que tiveram a comunicação como objeto de investigação em suas múltiplas dimensões e recortes temáticos.

Foram utilizados como critério de exclusão: artigos que somente tangenciaram a comunicação; quando a comunicação foi resultante de outros objetos investigados; e quando esta foi somente utilizada para subsidiar discussões de outras temáticas.

Os manuscritos, incluídos no corpus empírico, foram lidos e relidos a fim de classificá-los segundo o tipo de estudo realizado - se empírico, teórico, relato de experiência, estudo de revisão ou estudo de caso - e segundo as seções da revista que publicaram essa temática. Também foram identificados os campos temáticos, tendo como

\footnotetext{
1 Total de manuscritos publicados nas seções Artigos, Espaço Aberto Revisão, Dossiê, Notas Breves e Debates.
}

critério para a sua formação a presença de características similares que permitiram agrupá-los. Os manuscritos que não se adequaram a nenhuma classificação e apareceram em apenas um manuscrito foram identificados como "outros". Embora um único artigo pudesse estar presente em mais de um campo, optou-se por classificálo no campo temático que melhor o representasse. Em busca de uma maior especificidade para o estudo, foram identificadas categorias, a fim de expressar os diferentes temas abordados.

Para garantir a confiabilidade na codificação, os dados foram codificados pelo primeiro autor (APC), seguido pelo segundo autor (AL). Após a conclusão da codificação, foram feitas alterações no esquema de codificação para dirimir eventuais discordâncias identificadas a fim de alcançar $100 \%$ de concordância.

\section{Resultados}

\section{A produção sobre comunicação na Interface}

Foram selecionados 154 manuscritos que tiveram a comunicação como um dos seus objetos, o que representou $11,47 \%$ do total de 1.343 artigos publicados. Houve publicações com esse enfoque em praticamente todos os anos investigados, com exceção de 2001. Conforme mostra 0 gráfico 1 , há uma tendência de crescimento da produção nesta área, a despeito das oscilações anuais.

A temática da comunicação esteve presente em quase todas as seções da revista, mas majoritariamente na seção Artigos, conforme mostra a tabela 1. Essa seção publica textos analíticos ou de revisão oriundos de pesquisas originais teóricas ou de campo. Apresentando uma porcentagem próxima de publicações, apareceram as seções Espaço Aberto que engloba notas preliminares de pesquisa, textos que problematizam temas polêmicos e/ou atuais, relatos de experiência ou informações relevantes veiculadas em meio eletrônico ${ }^{2}$ - ; e Dossiê - que contempla ensaios ou textos analíticos temáticos a convite dos editores e resultantes de estudos e pesquisas.

Quanto ao tipo de estudo, destacaram-se os empíricos, seguidos dos teóricos. Os estudos de revisão e os estudos de caso foram os menos frequentes como mostra a tabela 2.

\footnotetext{
2 A partir de maio de 2016, essa seção se dedica exclusivamente a "textos embasados teoricamente que descrevam e analisem criticamente experiências relevantes para o escopo da revista", segundo especificado no site da revista.
} 


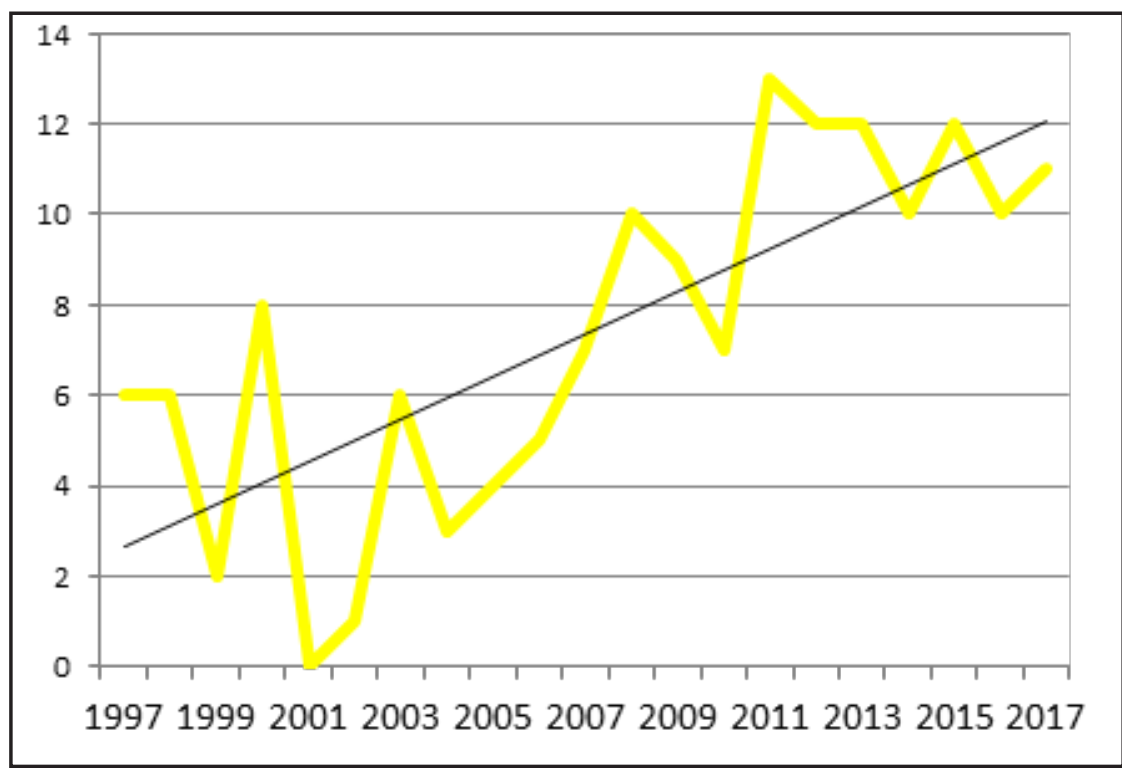

Gráfico 1. Número de artigos publicados sobre comunicação com linha de tendência no período de 1997 a 2017.

Tabela 1. Número de manuscritos publicados por seção, de 1997 a 2017.

\begin{tabular}{|l|c|c|}
\hline \multicolumn{1}{|c|}{ Seções } & N & Frequência \% \\
\hline Artigos & 104 & 67,53 \\
\hline Espaço aberto & 22 & 14,29 \\
\hline Dossiê & 18 & 11,69 \\
\hline Debates - artigo & 5 & 3,25 \\
\hline Debates - comentários & 4 & 2,60 \\
\hline Notas breves & 1 & 0,64 \\
\hline Total & 154 & $100 \%$ \\
\hline
\end{tabular}

Tabela 2. Tipo de estudos publicados na Interface de 1997 a 2017.

\begin{tabular}{|l|c|c|}
\hline Tipo de estudo & N & Frequência \% \\
\hline Empírico & 81 & 52,60 \\
\hline Teórico & 40 & 25,97 \\
\hline Relato de experiência & 20 & 12,99 \\
\hline Estudo de caso & 6 & 3,90 \\
\hline Estudo de revisão & 7 & 4,54 \\
\hline Total & 154 & $100 \%$ \\
\hline
\end{tabular}

Campos temáticos: diversidade e riqueza de abordagens

Os manuscritos selecionados foram agrupados em seis campos temáticos: "Mídias" (1), cujos artigos analisam a cobertura jornalística sobre temas da Saúde Coletiva - ou as redes sociais - ou discutiram a comunicação praticada pelos meios de comunicação; "Saúde Coletiva" (2), que concentra manuscritos que tematizaram as relações e o papel da comunicação nas suas várias dimensões nas práticas de Saúde Coletiva; "Formação profissional" (3), que contempla artigos que analisam a comunicação nos cursos de graduação em saúde e nas estratégias de formação continuada, bem como a abordagem da comunicação e saúde na formação dos profissionais de comunicação; "Relação profissional saúde, paciente/família e serviço" (4), que analisa as práticas comunicativas entre esses atores; as "Tecnologias de informação e comunicação (TIC)" (5), quando o foco dos artigos foram as TIC em seus usos e impactos na saúde; e "Comunicação e sociedade" (6), com abordagens centradas na comunicação sem estabelecer uma conexão com a saúde.

Quanto aos campos temáticos que concentraram o maior número de publicações, destacaram-se "Mídias" e "Saúde Coletiva", com 41 manuscritos cada um, representando juntos mais de $50 \%$ das publicações (tabela 3 ). 
Tabela 3. Campos temáticos e categorias presentes nas publicações de Interface no período de 1997 a 2017.

\begin{tabular}{|c|c|c|c|c|}
\hline $\begin{array}{c}\text { Campos } \\
\text { temáticos }\end{array}$ & Categorias & Autores & $\mathbf{N}$ & $\%$ \\
\hline \multirow[t]{7}{*}{ Mídias } & $\begin{array}{l}\text { Discursos } \\
\text { dos meios de } \\
\text { comunicação }\end{array}$ & $\begin{array}{l}\text { Soares, 1998; Lefévre, 1999; Bevilacqua et al, 2000; Rangel-S, } \\
\text { 2006; Vaz et al. 2007; Campos et al., 2009; Zucco \& Minayo, } \\
\text { 2009; Ortega et al., 2010; Soares \& Caponi, 2011; Stacheski \& } \\
\text { Massi, 2011; Santos \& Cardoso, 2011; Souza \& Brandão, 2012; } \\
\text { Cavaca et al., 2012; Díaz del Castillo et al., 2012; Rios et al., } \\
\text { 2015; Cavaca \& Vasconcellos-Silva, 2015; Cordeiro \& Kruse, } \\
\text { 2015; Sarudiansky, 2016; Lopes \& Araújo, 2017. }\end{array}$ & 19 & 12,34 \\
\hline & Redes sociais & $\begin{array}{l}\text { Costa, 2005; Montardo \& Passerino, 2010; Separavich \& } \\
\text { Canesqui, 2012; Ortega et al., 2013; Zago, 2013; Barros \& Serpa } \\
\text { Jr., 2014; Martorell et al., 2016; Sena \& Tesser, 2017; Teixeira et } \\
\text { al., 2016. }\end{array}$ & 9 & 5,84 \\
\hline & $\begin{array}{l}\text { Comunicação } \\
\text { midiática }\end{array}$ & $\begin{array}{l}\text { Rubim, 2000; Oliveira, 2000; Njaine \& Minayo, 2003; Njaine, } \\
\text { 2006; Romanini \& Roso, 2014; Thiago, Russo, \& Camargo } \\
\text { Junior, 2016. }\end{array}$ & 6 & 3,90 \\
\hline & $\begin{array}{l}\text { Divulgação } \\
\text { científica }\end{array}$ & $\begin{array}{l}\text { Cunha, 2008; Oliveira \& Epstein, 2009; Oliveira et al., 2009; Luz } \\
\text { et al., 2013. }\end{array}$ & 4 & 2,60 \\
\hline & Jornalismo & Ferreira, 2000; Kucinski, 2000. & 2 & 1,30 \\
\hline & Propaganda & Rabello \& Camargo Júnior, 2012. & 1 & 0,65 \\
\hline & Subtotal & & 41 & 26,62 \\
\hline \multirow[t]{5}{*}{$\begin{array}{l}\text { Saúde } \\
\text { Coletiva }\end{array}$} & $\begin{array}{l}\text { Práticas de } \\
\text { comunicação } \\
\text { e/ou educação } \\
\text { em saúde }\end{array}$ & $\begin{array}{l}\text { Cyrino \& Cyrino, 1997; Teixeira, 1997; Pitta, 1998; Marinho, } \\
\text { 2000; Oliveira, 2002; Queiroz \& Jorge, 2006; Kiss, Schraiber, \& } \\
\text { D'Oliveira, 2007; Rangel-S, 2008; Teixeira, 2008; Montoro, 2008; } \\
\text { Oliveira et al., 2008; Deslandes \& Mitre, 2009; Lima \& Rivera, } \\
\text { 2009; Ramalho e Oliveira et al., 2009; Kelly-Santos, Monteiro, } \\
\text { \& Ribeiro, 2010; Santos, Ribeiro, \& Monteiro, 2012; Guimarães } \\
\text { et al., 2010; Freitas \& Rezende Filho, 2011; Marteleto \& David, } \\
\text { 2014; Sampaio et al., 2014; Esteves, Antunes, \& Caires, 2014; } \\
\text { Omelczuk et al., 2015; Lindenmeyer \& Martins, 2015; Lima et al., } \\
\text { 2016; Garelli et al., 2017; Marques et al., 2017. }\end{array}$ & 26 & 16,88 \\
\hline & $\begin{array}{l}\text { Informação em } \\
\text { saúde }\end{array}$ & $\begin{array}{l}\text { Packer, 2005; Moraes, 2008; Santos et al., 2013; Leite et al., } \\
\text { 2014; Sanmartino et al., 2015; Oliveira et al., 2015; Pinto el al., } \\
\text { 2015. }\end{array}$ & 7 & 4,55 \\
\hline & $\begin{array}{l}\text { Comunicação } \\
\text { e políticas } \\
\text { públicas }\end{array}$ & $\begin{array}{l}\text { Pitta \& Magajewski, 2000; Araújo, 2004; Marinho, 2005; Pitta \& } \\
\text { Rivera, 2006. }\end{array}$ & 4 & 2,60 \\
\hline & $\begin{array}{l}\text { Comunicação e } \\
\text { Saúde Pública } \\
\end{array}$ & $\begin{array}{l}\text { Rojas-Rajs \& Soto, 2013; Oliveira, 2014; Araujo \& Mandú, 2016; } \\
\text { Lisboa \& Lerner, } 2017 .\end{array}$ & 4 & 2,60 \\
\hline & Subtotal & & 41 & 26,62 \\
\hline
\end{tabular}


Tabela 3. Continuação.

\begin{tabular}{|c|c|c|c|c|}
\hline $\begin{array}{l}\text { Campos } \\
\text { temáticos }\end{array}$ & Categorias & Autores & $\mathbf{N}$ & $\%$ \\
\hline \multirow[t]{4}{*}{$\begin{array}{l}\text { Formação } \\
\text { profissional }\end{array}$} & $\begin{array}{l}\text { Educação na } \\
\text { Saúde }\end{array}$ & $\begin{array}{l}\text { Novelli, 1997; Ramos-Cerqueira, 1997; Nobre et al., 2004; } \\
\text { Teixeira, 1997; Rossi \& Batista, 2006; Magalhães, 2007; } \\
\text { Tapajós, 2007; De Marco et al., 2010; Rios \& Schraiber, 2011; } \\
\text { Galato et al., 2011; Lanzieri et al., 2011; Sá \& Siqueira, 2011; } \\
\text { Romanholi \& Cyrino, 2012; Costa \& Silva, 2012; Oliveira et } \\
\text { al., 2012; Santos \& Noro, 2013; Silva et al., 2013; De Marco et } \\
\text { al., 2013; De Longhi et al., 2014; Liberali \& Grosseman, 2015; } \\
\text { Marcolino \& Reali, 2016. }\end{array}$ & 21 & 13,64 \\
\hline & Educação superior & $\begin{array}{l}\text { Moran, 1998; Mutti \& Axt, 2008; Ruiz-Moreno, Pittamiglio, \& } \\
\text { Furusato, 2008. }\end{array}$ & 3 & 1,95 \\
\hline & $\begin{array}{l}\text { Educação na } \\
\text { Comunicação }\end{array}$ & Kucinski, 1997; Meneguetti \& Gomes, 2009. & 2 & 1,30 \\
\hline & Subtotal & & 26 & 16,88 \\
\hline \multirow{5}{*}{$\begin{array}{l}\text { Relação } \\
\text { profissional, } \\
\text { pacientel } \\
\text { família e } \\
\text { serviço }\end{array}$} & $\begin{array}{l}\text { Relação médico- } \\
\text { paciente }\end{array}$ & $\begin{array}{l}\text { Zevallos Castañeda, 1999; Aciole, 2004; Favoreto \& Camargo } \\
\text { Jr., 2011; Aragon, 2003; Ruiz-Moral, 2007; Coelho Filho, 2007; } \\
\text { Sucupira, 2007; Borges \& D'oliveira, 2011; Mantilla \& Alonso, } \\
2011 .\end{array}$ & 9 & 5,84 \\
\hline & $\begin{array}{l}\text { Relação } \\
\text { profissional- } \\
\text { paciente }\end{array}$ & $\begin{array}{l}\text { Studart \& Acioli, 2011; Ayres et al., 2012; Passamai et al., } \\
\text { 2012; Correa \& Ribeiro, 2012; Junqueira et al., 2013; Moura, } \\
\text { Guimaraes, \& Luz, 2013; Bellenzani, Nemes, \& Paiva, 2013; } \\
\text { Aguiar \& Mota, 2014; Coriolano-Marinus et al., 2015. }\end{array}$ & 9 & 5,84 \\
\hline & $\begin{array}{l}\text { Relação } \\
\text { profissionais- } \\
\text { serviços }\end{array}$ & $\begin{array}{l}\text { Schraiber et al., 2003; Moura \& Rodrigues, 2003; Pereira, } \\
\text { Rivera, \& Artmann, 2013. }\end{array}$ & 3 & 1,95 \\
\hline & \begin{tabular}{|l|} 
Relação \\
profissionais-família
\end{tabular} & Furtado \& Leite, 2017. & 1 & 0,65 \\
\hline & Subtotal & & 22 & 14,29 \\
\hline $\begin{array}{l}\text { Tecnologias } \\
\text { de } \\
\text { Informação e } \\
\text { Comunicação }\end{array}$ & & $\begin{array}{l}\text { Paixão et al., 2011; Maia \& Struchiner, 2010; Castiel \& } \\
\text { Vasconcellos-Silva, 2003; Ribeiro, 1998; Jimenez, 2005; } \\
\text { Garbin, Pereira Neto, \& Guilam, 2008; Miranda \& Farias, } \\
\text { 2009; Camarotti, Kornblit, \& Di Leo, 2013; Nespoli, 2013; } \\
\text { Martins, \& Spink, 2015; Frossard \& Dias, 2016; Struchiner, } \\
\text { Ramos, \& Serpa Junior, 2016; Carvalho \& Struchiner, 2017; } \\
\text { Oliver-Mora \& Iniguez-Rueda, 2017. }\end{array}$ & 14 & 9,09 \\
\hline $\begin{array}{l}\text { Comunicação } \\
\text { e sociedade }\end{array}$ & & Rasco, 1998; Ribeiro, 2000. & 2 & 1,30 \\
\hline Outros & & $\begin{array}{l}\text { Ayres, 1997; Teixeira, 1998; Silva, 2003; Grossman, Araujo- } \\
\text { Jorge, \& Araujo, 2008; Fontanella et al., 2011; Lerner \& Vaz, } \\
\text { 2017; Junges et al., 2017, Ventura el al., } 2017 .\end{array}$ & 8 & 5,19 \\
\hline Total & & & 154 & $100 \%$ \\
\hline
\end{tabular}




\section{O campo temático Mídias}

Os manuscritos incluídos neste campo trouxeram a comunicação nas suas mais diversas manifestações - jornalismo, publicidade e propaganda - e formas impressa ou on-line, massiva ou especializada, além da presença das redes sociais. Contou com seis categorias, sendo as mais frequentes às relacionadas aos discursos dos meios de comunicação e às redes sociais (tabela 3).

Na primeira categoria, não houve mais de um artigo por tema, sendo que as investigações analisaram a cobertura jornalística relacionada a uma diversidade de doenças, tais como: Aids, doenças negligenciadas, fibromialgia, intoxicação ocupacional por benzeno, leishmaniose visceral, surto de legionella e depressão. Outros temas investigados foram aborto; autismo; crimes de exploração sexual de crianças e adolescentes; envelhecimento; loucura; morte; uso da Ritalina; saúde bucal; sexualidade feminina; genética humana e o uso do Viagra; e visão de saúde e doença.

$\mathrm{Na}$ maioria dos casos em que houve pesquisa empírica, os meios de comunicação analisados foram predominantemente jornais (dez artigos); jornais e revistas (três); e revistas (dois). Apenas um trabalho analisou notícias veiculadas em jornais e em programas de televisão (Díaz del Castillo et al., 2012). Não foi objeto de análise outros meios de comunicação, como as rádios ou sites de notícias.

Em relação aos veículos pesquisados, predominaram os jornais de maior circulação nacional: a Folha de São Paulo apareceu em 33\% dos artigos publicados seguido de $\mathrm{O}$ Globo. $\mathrm{O}$ restante foi composto por títulos de circulação regional, como os jornais do estado de Minas Gerais, do estado da Bahia, do Espírito Santo e do Paraná. As matérias veiculadas em revistas foram objeto de pesquisa em cinco artigos, sendo que a Veja, de circulação nacional, apareceu em quatro deles.

Dos 19 manuscritos analisados, apenas três voltaramse para alguma dimensão da produção de notícias: dois deles sobre os critérios de noticiabilidade utilizados no processo de seleção de notícia (Campos, Vieira e Mota, 2009; Cavaca e Vasconcellos-Silva, 2015) e o último, para os próprios jornalistas, ao analisar as narrativas e experiências dos profissionais de comunicação acerca da loucura (Santos e Cardoso, 2011).

$\mathrm{Na}$ categoria Redes Sociais, percebeu-se um aumento paulatino no número de publicações na Interface concomitante com a própria expansão da internet e das mídias sociais, com a primeira ocorrendo em 2010. Essa categoria reuniu nove artigos, que tiveram diferentes objetos e meios de investigação. O único tema que se repetiu em dois manuscritos foi o autismo. Dos meios analisados blog, redes de relacionamentos, Orkut e Facebook, este último foi objeto de dois artigos.

Em relação ao referencial teórico-metodológico empregado nas categorias Discursos dos Meios de Comunicação e Redes Sociais - que contemplaram 28 artigos, a maior concentração desse campo temático -, este se mostrou bastante diverso, trazendo a riqueza de possibilidades teóricas utilizadas no campo da comunicação e saúde, não sendo identificada uma tendência predominante. Ao mesmo tempo em que houve, em alguns casos, a utilização de mais de uma corrente teórica na mesma pesquisa, em outros, nem sempre houve uma referência direta ao quadro teórico utilizado.

Entretanto, pode-se destacar o emprego da análise do discurso (com base em autores como Foucault, Maingueneau, Bakhtin, Minayo), a análise de conteúdo (Bardin) e ainda a utilização de estudos netnográficos e socioantropológicos. Foi possível também identificar referências ao interacionismo simbólico (Erving Goffman); ciência da linguagem (Greimas); psicanálise (Lacan e Freud); construcionismo social e teoria da notícia(Traquina); análise de redes sociais (Granovetter); retórica (Aristóteles, Foucault); e inteligência coletiva (Lévy).

Para a produção de dados nos estudos empíricos de ambas as categorias, houve a predominância da pesquisa documental (de textos ou imagens) na maioria dos estudos realizados.

\section{O campo temático Saúde Coletiva}

Este campo temático contou com quatro categorias, sendo que predominaram os estudos sobre a categoria "Práticas de comunicação e/ou educação em saúde", contabilizando 26 manuscritos, e aqueles que trataram a questão da "Informação em saúde" - constituindo-se esta em mais uma categoria -, com sete artigos. Essas duas categorias concentraram a maioria dos manuscritos publicados nesse campo (tabela 3).

A primeira categoria trouxe, em alguns trabalhos, a análise de materiais informativos ou campanhas de prevenção, entre elas, sobre hanseníase e Aids, bem como as estratégias de comunicação empregadas nesse processo, sendo a comunicação vista como um dos desafios a ser enfrentado no campo da saúde.

Ainda na perspectiva de produtos educativos, houve estudos que se voltaram para as experiências de 
educação sanitária do Estado de São Paulo na primeira metade do século XX. A comunicação e a educação, em uma perspectiva de humanização dos espaços, também foram completadas em alguns manuscritos relacionados a práticas de cinema e intervenção de palhaços na pediatria hospitalar. A comunicação e a formação de vínculos entre profissionais e usuários e a integração de serviços de saúde como uma ação comunicativa também foram objetos investigados.

Foi tema de discussão as práticas de educação, comunicação e mobilização comunitárias, como no caso do combate à dengue, assim como o relato de um projeto de cooperação envolvendo universidade, serviços de saúde e organizações comunitárias.

A segunda categoria, que se destacou neste campo temático, foi relacionada à "Informação em saúde", que contou com sete manuscritos. Foram temas de análise a informação sobre a doença de Chagas na perspectiva das pessoas afetadas; o conhecimento de pessoas surdas relacionadas à saúde e à doença; e a análise de vídeos utilizados como suportes informacionais nas ações de intervenção social na área da saúde. A produção de informação sobre raça/cor da pele dos corpos submetidos à necrópsia e o relato sobre um grupo informativo relacionado ao uso de drogas também foram contemplados. A informação científica em saúde esteve presente na análise sobre a origem da Biblioteca Virtual em Saúde (BVS).

Em relação ao referencial teórico-metodológico empregado nessas categorias, ocorre algo similar ao já descrito no campo Mídias: diversidades de enfoques, não havendo uma tendência predominante, além de nem sempre constar uma informação precisa sobre o quadro teórico empregado. Todavia, pode-se destacar o uso da análise de conteúdo (Bardin) e de discurso (Orlandi); e referência a autores como Pierre Lèvy, Minayo, Paulo Freire, Geertez, Lefèvre, Habermas, Austin, Echeverria, Bourdieu, Thompson e Gramsci.

\section{Campo temático Formação profissional}

Este campo temático contou com três categorias, sendo "Educação na saúde" a que concentrou o maior número de publicações (tabela 3). A maioria delas trouxe a educação médica ou os cursos de graduação em Medicina de universidades paulistas como objeto de investigação.

Quanto à abordagem, foi possivel identificar a predominância de três eixos principais na categoria "Educação na saúde". O primeiro problematizou o processo de ensino-aprendizagem, em que a comunicação apareceu na relação professor-aluno na prática pedagógica, nas atividades em sala de aula ou no processo ensinoaprendizagem da comunicação na consulta médica.

0 segundo eixo abordou a qualificação dos estudantes no que se refere a suas habilidades comunicacionais para a realização de entrevistas, observação e atendimento ao paciente utilizando diversas técnicas, entre elas, recursos audiovisuais, uso de psicodrama e jogos educativos. Predominaram os relatos de experiência relacionados à graduação médica, com exceção de dois estudos que envolveram alunos de graduação de outras áreas da saúde.

O terceiro eixo agrupou discussões teóricas e reflexões sobre a formação profissional em saúde, tais como práticas extensionistas no campo da saúde e os conceitos de humanização e humanidades e a sua relação com a comunicação nesse processo.

Campo temático relação profissional, paciente/ família e serviço

Este campo temático contou com quatro categorias. Dos 22 manuscritos, nove deles estavam vinculados à categoria relação médico-paciente e nove, relacionados à relação profissional-paciente.

$\mathrm{Na}$ primeira categoria, a maioria dos artigos foi composta por estudos teóricos. São exemplos expressivos de alguns desses estudos os que seguem: a relação médico-paciente a partir da racionalidade científica de matriz biológica e das questões estruturais e conjunturais que organizam a prática profissional do médico; e a incorporação da narrativa como possibilidade de ampliar o saber e prática clínica no âmbito da atenção primária à saúde.

Em relação aos estudos empíricos, uma pesquisa analisou as práticas discursivas e as múltiplas vozes - dos médicos, dos locutores e dos pacientes - na construção do corpo durante um programa de consultório médico de uma emissora de rádio peruana. Outro trabalho recorreu ao método cartográfico para trazer a possibilidade de a cena médica abrir-se para possibilidades de comunicação que ultrapassassem a relação médico-paciente.

\section{O campo temático Tecnologias de Informação e Comunicação}

No campo temático TIC, que reuniu 14 manuscritos, não houve a necessidade de apresentar classificações. Alguns artigos trouxeram uma perspectiva crítica sobre autilização das tecnologias na área da saúde, como a abrangência das TIC que produzem setores especializados, tais como e-saúde, telemedicina, cibermedicina e informática para a saúde do consumidor. Já outros analisaram as 
possibilidades e implicações dessas estratégias, como o uso pedagógico das ferramentas da web 2.0 nos cursos de saúde, ou mesmo a inclusão digital na área da saúde.

\section{O campo temático Comunicação e Sociedade}

Esse campo temático - composto por dois artigos caracterizou-se por trazer abordagens mais amplas e centradas na comunicação sem estabelecer uma conexão com a saúde. Esses artigos fazem parte de um período em que a revista não havia especificado o escopo em seu expediente - o que só ocorreu em 2002. A partir desse momento, a revista deixava claro que os manuscritos submetidos deveriam explorar a articulação da comunicação e da educação com a saúde (Cyrino et al., 2015).

\section{Discussão e conclusões}

No período $1997-2017,11,47 \%$ (154) do total dos artigos publicados (1.343) pela Interface tiveram a comunicação como um dos seus objetos. A produção sobre comunicação se manteve todos os anos, exceto em 2001. O ano de 2008 marca um pico de crescimento expressivo que poderia estar relacionado às intervenções, nesse período, de questões relativas tanto ao mesmo campo (por exemplo, a questão do processo marcado pela construção do campo e encaminhado a sua consolidação acadêmica) como externo a ele (por exemplo, as questões do crescimento da pós-graduação e da maior exigência de publicação dos pesquisadores).

Em relação às seções da revista, mais da metade das publicações se encontram na seção Artigos (67,53\%), fato intimamente relacionado ao tipo de estudo predominante: $52,60 \%$ correspondem a estudos empíricos. Destacamse ainda os estudos teóricos, como a segunda categoria com mais artigos: três de dez manuscritos sobre comunicação fazem parte desse rol $(25,97 \%)$.

A diversidade temática dos artigos - Mídias (26,62\%); Saúde Coletiva (26,62\%); Formação profissional (16,88\%); Relacionamento profissional, paciente e serviço (14,29\%); Tecnologias de Informação e Comunicação $(9,09 \%)$; e Comunicação e Sociedade (1,30\%) - evidencia a heterogeneidade e riqueza do campo Comunicação e Saúde. Para Petracci $(2015$, p. 15):

Lejos de considerarla un obstáculo, leo esa "heterogeneidad" en clave positiva. De ella emergieron fortalezas del campo a través de una producción que permitió comprender procesos individuales y subjetivos sobre los comportamientos en salud, mejorar diseños y planificaciones institucionales, y analizar críticamente procesos político-comunicacionales propios del espacio público. [...] A partir de la confluencia, la profusa actividad en terreno y la producción académica, las fortalezas alcanzadas y los desafíos teóricos, conceptuales, metodológicos y prácticos pendientes, se desarrolló y sigue expandiéndose, con logros y carencias, un campo de conocimiento heterogéneo atravesado por las tensiones y los conflictos de la trama comunicacional contemporánea.

Todos os tópicos estão inter-relacionados, mas 0 lugar de destaque ocupado pelo campo temático Mídias não faz mais do que refletir a relevância que, conceitual e empiricamente, tem os meios de comunicação como parte importante da construção da realidade social (Charaudeau, 2005). Podem ser entendidos tanto como laço social - na medida em que pulverizam valores simbólicos que podem ser compartilhados - quanto comportamental, enquanto referência a padrões e comportamentos (Oliveira, 2013).

Os dados analisados refletem ainda o papel do jornalismo em geral e a maior profissionalização do jornalismo em saúde nessas mensagens. Nos estudos investigados, houve a predominância da análise da mídia impressa. Esses achados são similares aos de CatalanMatamoros \& Peñafiel-Saiz, (2017), Terrón et al., (2017) e Langbecker et al. (2019), não sendo objeto de estudos programas de rádio e sites de notícias. Somente um artigo investigou programas de televisão.

Entretanto, não é possível considerar que todos os meios sejam igualmente determinantes e impositores de conceitos e comportamentos. Cada um deles tem um ethos próprio, com especificidades por parte tanto de seus enunciadores quanto de seus públicos (Xavier, 2006; Sampaio, 2011); daí a importância de incluir em futuras análises programas de rádio, de televisão e de sites de notícias, possibilitando assim abarcar diferentes formatos e audiências.

Além disso, este lugar de destaque do jornalismo durante 0 século $X X$ e 0 atual vem sofrendo mudanças diante do desenvolvimento das redes sociais e das novas tecnologias de comunicação em geral. 0 rápido crescimento da internet e das mídias sociais refletem 0 seu entrelaçamento à vida cotidiana. Com essa expansão, a centralidade na seleção dos fatos que são publicizados, comumente atribuída aos meios de comunicação, vem perdendo espaço para esses novos formatos, trazendo outras possibilidades de divulgação e circulação de discursos, informação e opiniões, o que poderia impactar na produção científica. Essas mudanças abrem outras vias de investigação na área de comunicação e saúde.

Nos estudos analisados, a categoria Redes Sociais contou apenas com nove artigos, o que indica a necessidade de novas pesquisas sobre essas plataformas, bem como 
a análise de outras mídias sociais para além do Facebook, como o caso do YouTube, Instagram e Twitter.

Uma análise prévia, bem como as conclusões de Terrón et al. (2017), coloca a Interface em um lugar pioneiro e promotor de publicações sobre comunicação em saúde. Se anteriormente assinalamos que, na América Latina, o campo está localizado entre a construção e a consolidação, a Interface contribuiu para o fortalecimento do campo da Comunicação e da Saúde por meio de aportes sobre teoria e prática; sobre pesquisa e avaliação como base para a comunicação de políticas públicas de saúde e incidência pública e política; sobre 0 lugar da comunicação no ensino de médicos e de outros profissionais de saúde; entre outros.

Todavia, a baixa produção sobre comunicação, representando $11,47 \%$ do total de manuscritos publicados, em uma revista que conta com essa especificidade em seu escopo expressa ainda a incipiência da comunicação nas investigações no âmbito da Saúde Coletiva. Para Terrón et al. (2017), a comunicação, como campo, não está na agenda das revistas de saúde pública, o que coloca a interdisciplinaridade entre os campos da comunicação e da saúde como um desafio a ser vencido.

\section{Agradecimentos}

Agradecemos a equipe da revista Interface, especialmente a Juliana Freitas Oliveira, e a equipe da Unidade de Pesquisa em Saúde Coletiva (UPESC) da Faculdade de Medicina de Botucatu, Unesp, responsável pela organização do banco de dados das publicações da revista Interface.

\section{Referências bibliográficas}

Aciole, G.G. (2004). O lugar, a teoria e a prática profissional do médico: elementos para uma abordagem crítica da relação médico-paciente no consultório. Interface (Botucatu), 8(14), 95-112. doi: https://doi.org/10.1590/S1414-32832004000100006.

Aguiar, M.E., \& Mota, A. (2014). O Programa Saúde da Família no bairro do Bom Retiro, SP, Brasil: a comunicação entre bolivianos e trabalhadores de saúde. Interface (Botucatu), 18(50), 493-506. doi: https://doi.org/10.1590/1807-57622013.0040.

Aragon, L.E.P. (2003). A espessura do encontro. Interface (Botucatu), 7(12), 11-22. doi: https://doi. org/10.1590/S1414-32832003000100002.

Araújo, I.S., \& Cardoso, J. M. (2007). Comunicação e saúde. Rio de Janeiro: ed. Fiocruz.
Araújo, I.S. (2004). Mercado Simbólico: um modelo de comunicação para políticas públicas. Interface (Botucatu), 8(14), 165-178. doi: https://doi. org/10.1590/S1414-32832004000100010.

Araujo, N.B., \& Mandú, E.N.T. (2016). Produção de sentidos entre adolescentes sobre o cuidado de si na gravidez. Interface (Botucatu), 20(57), 363-375. doi: $10.1590 / 1807-57622015.0301$

Ayres, J. R.C.M. Razão, ciência e pedagogia da emancipação. (1997). Interface (Botucatu), 1(1), 95-108. doi: https://doi.org/10.1590/S141432831997000200007

Ayres, J.R.C.M., Carvalho, Y.M., Nasser, M.A., Saltão, R.M, \& Mendes, V.M. (2012). Caminhos da integralidade: adolescentes e jovens na Atenção Primária à Saúde. Interface (Botucatu), 16(40), 67-82. doi: https://doi. org/10.1590/S1414-32832012005000021.

Barros, O.C., \& Serpa Júnior, O.D. (2014). Ouvir vozes: um estudo sobre a troca de experiências em ambiente virtual. Interface (Botucatu), 18(50), 557-569. Doi: https://doi.org/10.1590/1807-57622013.0680

Bellenzani, R.N., Baptistella M.I., \& Paiva, V. (2013). Comunicação profissional-paciente e cuidado: avaliação de uma intervenção para adesão ao tratamento de HIV/Aids. Interface (Botucatu), 17(47), 803-834. https://doi.org/10.1590/180757622013.0051 .

Bertol, S.R.S. (2012). Gravidez de adolescentes na mídia impressa. Organicom, 9(16/17), 223-241. https://doi. org/10.11606/issn.2238-2593.organicom.2012.139140

Bevilacqua, P.D., Paixão, H.H., Castro, M.C.P.S., \& Modena, C.M. (2000). Leishmaniose visceral: história jornalística de uma epidemia em Belo Horizonte, Brasil. Interface (Botucatu), (4)7, 83-102. http:// dx.doi.org/10.1590/S1414-32832000000200007.

Borges, R., \& D'Oliveira, A.F.P.L. (2011). A visita médica domiciliar como espaço para interação e comunicação em Florianópolis, SC. Interface (Botucatu), 15(37), 461-472.

Camarotti, A.C., Kornblit, A.L., \& Di Leo, P.F. (2013). Prevención del consumo problemático de drogas en la escuela: estrategia de formación docente en Argentina utilizando TIC. Interface (Botucatu), 17(46), 695-703. http://dx.doi.org/10.1590/S1414-32832013005000023. 
Campos, M.A.T.F., Vieira, C.D.D., \& Mota, J.A.C. (2009). A infância sem segredos: a noticiabilidade jornalística do crime de exploração sexual de crianças e adolescentes. Interface (Botucatu), 13(30), 17-29. http://dx.doi.org/10.1590/S141432832009000300003.

Cardoso, J. M., \& Rocha, R.L. (2018). Interfaces e desafios comunicacionais do Sistema Único de Saúde. Ciencia \& Saude Coletiva, 23(6), 18711880. $10.1590 / 1413-81232018236.01312018$

Carvalho, R.A., \& Struchiner, M. (2017). Conhecimentos e expertises de universidades tradicionais para o desenvolvimento de cursos a distância da Universidade Aberta do Sistema Único de Saúde (UNA-SUS). Interface (Botucatu), 21(63), 991-1003. https://doi.org/10.1590/1807-57622016.0027.

Castañeda, M.M.Z. (1999). Voces y cuerpos. El consultorio médico radial como espacio discursivo en el Perú. Interface (Botucatu), 3(4), 75-92. doi: https://doi.org/10.1590/S1414-32831999000100007

Castiel, L. D., \& Vasconcellos-Silva, P. R. (2003). A interface internet/s@úde: perspectivas e desafios. Interface (Botucatu), 7(13), 47-64. https://doi. org/10.1590/S1414-32832003000200004.

Cavaca, A.G., \& Vasconcellos-Silva, P.R. (2015). Doenças midiaticamente negligenciadas: uma aproximação teórica. Interface (Botucatu), 19(52), 83-94. https:// doi.org/10.1590/1807-57622014.0205

Cavaca, A.G., Gentilli, V., Marcolino, E.M., \& Emmerich, A. (2012). As representações da saúde bucal na mídia impressa. Interface (Botucatu), 16(43), 1055-68. https://doi.org/10.1590/S1414-32832012005000039

Charaudeau, P. (2005). ¿Nos manipulanlos medios? Cuadernos de Información y Comunicación, (10), 319-30. https://dx.doi.org/10.5209/CIYC

Cordeiro, F.R., \& Kruse, M.H.L. (2015). A produção do currículo do final da vida por meio do dispositivo pedagógico da mídia. Interface (Botucatu), 19(55), 1193-205. https://doi.org/10.1590/180757622014.0199

Coriolano-Marinus, M.W.L., Andrade R.S., Ruiz-Moreno L., \& Lima, L.S. (2015). Comunicação entre trabalhadores de saúde e usuários no cuidado à criança menor de dois anos no contexto de uma unidade de saúde da família. Interface (Botucatu), 19(53), 311-324. 10.1590/1807-57622013.0552
Corrêa, G.T., \& Ribeiro, V.M.B. (2012). Dialogando com Bakhtin: algumas contribuições para a compreensão das interações verbais no campo da saúde. Interface (Botucatu), 16(41), 331-342. https://doi.org/10.1590/ S1414-32832012005000023

Costa, L.S.M., \& Silva, N.C.Z. (2012). Desenvolvendo atitudes, conhecimentos e habilidades dos estudantes de medicina na atenção em saúde de pessoas surdas. Interface (Botucatu), 16(43), 1107-17. https://doi.org/10.1590/S1414-32832012005000051

Costa, R. (2005). Por um novo conceito de comunidade: redes sociais, comunidades pessoais, inteligência coletiva. Interface (Botucatu), 9(17), 235-248. https://doi.org/10.1590/S1414-32832005000200003.

Cuberli, M. (2008). Perspectivas comunicacionales para pensar las prácticas en salud: pasado y presente de un campo en construcción. Question, 1(18), 1-6. Recuperado de https://perio.unlp.edu.ar/ojs/index. php/question/article/view/524/443

Cuberli, M., \& Soares de Araújo, I. (2015). Las prácticas de la comunicación y salud: intersecciones e intersticios. En: M. Petracci. La salud en la trama comunicacional contemporánea. Buenos Aires: Prometeo.

Cunha, R.B. (2008). Do científico ao jornalístico: análise comparativa de discursos sobre saúde. Interface (Botucatu), 12(24), 195-203. https://doi.org/10.1590/ S1414-32832008000100015

Cyrino, A.P., \& Cyrino, E.G. (1997). Integrando Comunicação, Saúde e Educação: experiência do UNI-Btu. Interface (Botucatu), 1(1). https://doi. org/10.1590/S1414-32831997000200012

Cyrino, A.P., Lima, E.A., Garcia, V.L., Teixeira, R.R., Foresti, M.C.P.P., \& Schraiber, L.B. (2015). Um espaço interdisciplinar de comunicação científica na Saúde Coletiva: a revista Interface - Comunicação, Saúde, Educação. Ciência \& Saúde Coletiva, 20(7), 2059-2068. https://doi.org/10.1590/141381232015207.05942015

De Longhi, A.L., Bermudez, G.M.A., Abensur, P.L.D., \& Ruiz-Moreno, L. (2014). Una estrategia didáctica para la formación de educadores de salud en Brasil: la indagación dialógica problematizadora. Interface (Botucatu), 18(51), 759-69. https://doi. org/10.1590/1807-57622013.0967

De Marco, M.A., Degiovani, M.V., Torossian, M.S., Wechsler, R., Joppert, S.M.H., \& Lucchese, A.C. 
(2013). Comunicação, humanidades e humanização: a educação técnica, ética, estética e emocional do estudante e do profissional de saúde. Interface (Botucatu), 17(46), 683-93. https://doi.org/10.1590/ S1414-32832013005000017

De Marco, M.A., Vessoni, A.L., Capelo, A., \& Dias, C.C. (2010). Laboratório de comunicação: ampliando as habilidades do estudante de medicina para a prática da entrevista. Interface (Botucatu), 14(32), 217-27. https://doi.org/10.1590/S1414-32832010000100018

Deslandes, S.F., \& Mitre, R.M.A. (2009). Processo comunicativo e humanização em saúde. Interface (Botucatu), 13(supl.1), 641-9. https://doi.org/10.1590/ S1414-32832009000500015

Díaz del Castillo, A., Olarte Sierra, M.F., \& Pérez-Bustos, T. (2012). Testigos modestos y poblaciones invisibles en la cobertura de la genética humana en los medios de comunicación colombianos. Interface (Botucatu), 16(41), 451-67. https://doi.org/10.1590/S141432832012000200013

Esteves, C.H., Antunes, C., \& Caires S. (2014). Humanização em contexto pediátrico: o papel dos palhaços na melhoria do ambiente vivido pela criança hospitalizada. Interface (Botucatu), 18(51), 697-708.

Favoreto, C.A.O., \& Camargo Jr, K.R. (2011). A narrativa como ferramenta para o desenvolvimento da prática clínica. Interface (Botucatu), 15, 473-483.

Ferreira, L.A. (2000). Intencionalidade, jornalismo opinativo e leitura. Interface (Botucatu), 4(6), 187-192.

Coelho Filho, J.M. (2007). Relação médico-paciente: a essência perdida. Interface (Botucatu), 11(23), 631-633.

Fontanella, B.J.B., Demarzo, M.M.P., Mello, G.A., \& Fortes, S.L.C.L. (2011). Os usuários de álcool, Atenção Primária à Saúde e o que é "perdido na tradução". Interface (Botucatu), 15(37), 573-585.

Freitas, F.V., \& Rezende Filho, L.A. (2011). Modelos de comunicação e uso de impressos na educação em saúde: uma pesquisa bibliográfica. Interface (Botucatu), 15, 243-256.

Frossard, V.C., \& Dias, M.C.M. (2016). O impacto da internet na interação entre pacientes: novos cenários em saúde. Interface (Botucatu), 20(57), p.349-361.

Furtado, M.E.M.F., \& Leite, D.M.C. (2017). Cuidados paliativos sob a ótica de familiares de pacientes com neoplasia de pulmão. Interface (Botucatu), 21(63), 969-980.

Galato, D., Alano, G.M., França, T.F., \& Vieira, A.C. (2011). Exame Clínico Objetivo Estruturado (ECOE): uma experiência de ensino por meio de simulação do atendimento farmacêutico. Interface (Botucatu), 15(36), 309-19.

Garbin, H.B.R., Pereira Neto, A.F., \& Guilam, M.C.R. (2008). A internet, o paciente expert e a prática médica: uma análise bibliográfica. Interface (Botucatu), 12(26), 579-588.

Garelli, F., Sanmartino, M., \& Dumrauf, A. (2017). Análisis de materiales didácticos e informativos sobre dengue em Argentina. Interface (Botucatu), 21(60), 35-49.

Grossman, E.A.J., Tania C., \& Araújo, I. S. (2008). A escuta sensivel: um estudo sobre o relacionamento entre pessoas e ambientes voltados para a saúde. Interface (Botucatu), 12, (25), 309-324.

Guimarães, M.C.S., Silva, C.H., Souza, R.A., Santos, R.T., Silva, L.R. (2010). Educação sanitária em 16mm: memória audiovisual do Serviço Especial de Saúde Pública - SESP. Interface (Botucatu), 14(32), 23-34.

Iturrizaga, A.U. Epílogo. En U. Cuesta, T. Menéndez, \& A. Ugarte, (org.). (2011). Comunicación y salud - Nuevos escenarios y tendencias. Madrid: ed. Complutense.

Jiménez, R.V. (2005). Educación, poder y mercado: deconstrucción crítica de los efectos disciplinantes de las TIC en la nueva Escuela del Espectáculo. Interface (Botucatu), 9(18), 475-488.

Junges, J.R., Fernandes, R.B.P., Herbert, N.D.R., Tomasini, F., Werle , L., Pereira, C., \& Moretti, A.W. (2017). O cuidado longitudinal difícil de uma usuária em situação de grave cronicidade: análise de caso emblemático. Interface (Botucatu), 21(62), 651-659.

Junqueira, L.C.U, Vieira, E.M., Giami, A, \& Santos, M.A. (2013). Análise da comunicação acerca da sexualidade, estabelecida pelas enfermeiras, com pacientes no contexto assistencial do câncer de mama. Interface (Botucatu), 17(44), 89-101.

Kelly-Santos, A., Monteiro, S.S., \& Ribeiro, A.P.G. (2010). Acervo de materiais educativos sobre hanseníase: um dispositivo da memória e das práticas comunicativas. Interface (Botucatu), 14(32), 37-51. 
Kiss, L.B., Schraiber, L.B. \& d'Oliveira, A.F.P.L. (2007). Possibilidades de uma rede intersetorial de atendimento a mulheres em situação de violência. Interface (Botucatu), 11(23), 485-501.

Kucinski, B. (2000). Jornalismo, saúde e cidadania. Interface (Botucatu), 4(6), 181-186.

Kucinski, B. (1997). Jornalismo, saúde e cidadania. Interface (Botucatu), 1(1), 209-212.

Langbecker, A., Castellanos, M.E.P., Neves, R.F., \& Catalan-Matamoros, D. (2019). A cobertura jornalística sobre temas de interesse para a Saúde Coletiva brasileira: uma revisão de literatura. Interface (Botucatu), 23, e1800095. doi: https://doi. org/10.1590/Interface.180095

Lanzieri, P.G., Claro, L.B.L., Bragança, F.C.R., Montezano, V.R.S., \& Silva, C.S. (2011). "Boa noite, bom dia HUAP!", uma experiência de humanização na formação de profissionais da área de saúde. Interface (Botucatu), 15(36), 289-97.

Lefévre, F. (1999). Jornal, saúde, doença, consumo,Viagra e Saia Justa. Interface (Botucatu), 3(4), 63-72.

Leite, R.A.F., Brito, E.S., Silva, L.M.C., Palha, P.F., \& Ventura, C.A.A. (2014). Acesso à informação em saúde e cuidado integral: percepção de usuários de um serviço público. Interface (Botucatu), 18(51), 661-71.

Lerner, K., \& Vaz, P. (2017). "Minha história de superação": sofrimento, testemunho e práticas terapêuticas em narrativas de câncer. Interface (Botucatu), 21(60), 153-163.

Liberali, R., \& Grosseman, S. (2015). Uso de Psicodrama em medicina no Brasil: uma revisão de literatura. Interface (Botucatu), 19(54), 561-71.

Lima, J.C., Rivera, F.J.U., \& Artmann, E. (2016). Análise do discurso argumentativo na coordenação de um Serviço de Atendimento Móvel de Urgência. Interface (Botucatu), 20(56), 51-63.

Lima, J.C., \& Rivera, F.J.U. (2009). Agir comunicativo, redes de conversação e coordenação em serviços de saúde: uma perspectiva teórico-metodológica. Interface (Botucatu), 13(31), 329-342.

Lindenmeyer, L. \& Martins, C.M. (2015). Comunicação e saúde nos manuais dos organismos internacionais para situações de emergência e desastre: intervenção e hegemonia. Interface (Botucatu), 19(53), 299-310.
Lisboa, M.R., \& Lerner, K. (2017). Sentidos de saúde, cuidado e risco para adolescentes residentes na favela da Maré, no Rio de Janeiro, Brasil. Interface (Botucatu), 21, (63), 893-906.

Lopes, F., \& Araújo, R. (2017). Um grande surto de Legionella ausente do debate público. Interface (Botucatu), 21(63), 957-67.

Lotero-Echeverri, G., Romero-Rodríguez, L.M, \& PérezRodríguez,A. (2019). Tendencias de las publicaciones especializadas en el campo de la educomunicación y alfabetización mediática en Latinoamérica. Interface (Botucatu), 23, e180193. doi: 23: e180193 https:// doi.org/10.1590/Interface.180193

Luz, M.T., Sabino, C., Mattos, R.S., Ferla, A.A., Andres, B., Alba, R.D., ... Assimos, R. (2013). Contribuição ao estudo do imaginário social contemporâneo: retórica e imagens das biociências em periódicos de divulgação científica. Interface (Botucatu), 17, (47), 901-912.

Magalhães, C.R. (2007). O jogo como pretexto educativo: educar e educar-se em curso de formação em saúde. Interface (Botucatu), 11(23), 647-54.

Maia, F., \& Struchiner, M. (2010). Utilização dos Weblogs e de Comunidades do Orkut como Ferramentas Pedagógicas em cursos da área da saúde. Interface (Botucatu), 14(35), 905-918.

Mantilla, M.J., \& Alonso, J.P. (2015). Transmisión del diagnóstico en psiquiatría y adscripción de identidades: perspectivas de los profesionales. Interface (Botucatu), 19(52), 21-32. http://dx.doi. org/10.1590/S1414-32832010005000025

Marcolino, T.Q., \& Reali, A.M.M.R. (2016). Crônica do grupo: ferramenta para análise colaborativa e melhoria da reflexão na pesquisa-ação. Interface (Botucatu), 20(56), 65-76.

Marinho, M.B. (2000). Entre o funcional e o lúdico: a camisinha nas campanhas de prevenção da Aids. Interface (Botucatu), 4(6), 103-110.

Marinho, M.B. (2005). O demônio nos "paraísos artificiais": considerações sobre as políticas de comunicação para a saúde relacionadas ao consumo de drogas. Interface (Botucatu), 9(17), 343-354.

Marques, M.C.C., Brasileiro, D.F., \& Fernandes, S.C.G. (2017). Informação e disciplina: a Coletânea de Educação Sanitária do estado de São Paulo, Brasil (1939-1952). Interface (Botucatu), 21(61), 397-410. 
Marteleto, R.M., \& David, H.M.S.L. (2014). Almanaque do Agente Comunitário de Saúde: uma experiência de produção compartilhada de conhecimentos. Interface (Botucatu), 18(Supl 2), 1211-1226.

Martins, M.H.M., \& Spink, M.J.P. (2015). O uso de tecnologias de comunicação de riscos de desastres como prática preventiva em saúde. Interface (Botucatu), 19(54), 503-514.

Martorell, L.B., Nascimento, W.F., \& Garrafa, V. (2016). Redes sociais, privacidade, confidencialidade e ética: a exposição de imagens de pacientes no facebook. Interface (Botucatu), 20(56), 13-23.

Matos, M.R., Meneguetti, L.C., \& Gomes, A.L.Z. (2009). Uma experiência em comunicação e saúde. Interface (Botucatu), 13(31), 437-447.

Miranda, L.M., \& Farias, S.F. (2009). As contribuições da internet para o idoso: uma revisão de literatura. Interface (Botucatu), 13(29), 383-394.

Montardo, S.P., \& Passerino, L.M. (2010). Implicações de redes temáticas em blogs na Análise de Redes Sociais (ARS): estudo de caso de blogs sobre autismo e síndrome de Asperger. Interface (Botucatu), 14(35), 921-31.

Montoro, T. (2008). Retratos da comunicação em saúde: desafios e perspectivas. Interface (Botucatu), 12(25), 442-51.

Moraes, A.F. (2008). A diversidade cultural presente nos vídeos em saúde. Interface (Botucatu), 12(27), 811-22.

Njaine, K., \& Minayo, M.C.S. (2003). Violência na escola: identificando pistas para a prevenção. Interface (Botucatu), 7(13), 119-134.

Moran, J.M. (1998). Internet no ensino universitário: pesquisa e comunicação na sala de aula. Interface (Botucatu), 2(3), 125-130.

Moura, E.R.F., \& Rodrigues, M.S.P. (2003). Comunicação e informação em Saúde no pré-natal. Interface (Botucatu), 7(13), 109-118.

Moura, M.M.D., Guimarães, L.M.B., \& Luz, M. (2013). Tocar: atenção ao vínculo no ambiente hospitalar. Interface (Botucatu), 17(45), 393-404.

Mutti, R.M.V., \& Axt, M. (2008). Para uma posição enunciativa no discurso pedagógico mediado por ambientes virtuais de aprendizagem. Interface (Botucatu), 12(25), 347-361.

Nespoli, G. (2013). Os domínios da Tecnologia Educacional no campo da Saúde. Interface (Botucatu), 17(47), 873-884.

Njaine, K. (2006). Sentidos da violência ou a violência sem sentido: 0 olhar dos adolescentes sobre a mídia. Interface (Botucatu), 10(20), 381-392.

Nobre, M.E.C., Domingues, R.Z.L., \& Yamaguishi, R.Z. (2004). Relato do aprendizado em estágio de observação da prática médica. Interface (Botucatu), 8(15), 381-6.

Novelli, P.G. (1997). A sala de aula como espaço de comunicação: reflexões em torno do tema. Interface (Botucatu), 1, 1, 43-50.

Oliveira, A., Silva Neto, J.C., Machado, M.L.T., Souza, M.B.B., Feliciano, A.B., \& Ogata, M.N. (2008). A comunicação no contexto do acolhimento em uma unidade de saúde da família de São Carlos, SP. Interface (Botucatu), 12(27), 749-62.

Oliveira, F. A. (2002). Antropologia nos serviços de saúde: integralidade, cultura e comunicação. Interface (Botucatu), 6(10), 63-74.

Oliveira, J.A., \& Epstein, I. (2009). Tempo, ciência e consenso: os diferentes tempos que envolvem a pesquisa científica, a decisão política e a opinião pública. Interface (Botucatu), 13(29), 423-433.

Oliveira, M. S., Paiva, L.H.C., Costa, J.V., \& Pinto-Neto, A.M. (2009). Saúde da mulher na imprensa brasileira: análise da qualidade científica nas revistas semanais. Interface (Botucatu), 13(30), 07-16.

Oliveira, M.L.C. (2014). Vozes em sintonia: Educação Popular sobre DST via rádio comunitária. Interface (Botucatu), 18(suppl.2), 1523-1528.

Oliveira, V.C. (2013). Os sentidos da saúde nas mídias jornalísticas impressas. Revista Eletrônica de Comunicação, Informação, Inovação em Saúde, 6(4), 1-14. doi://dx.doi.org/10.3395/reciis.v6i4.622

Oliveira, V.C. A. comunicação midiática e o Sistema Único de Saúde. (2000). Interface (Botucatu), 4(7), 71-80.

Oliveira, Y.C.A., Celino, S.D.M., França, I.S.X., Pagliuca, 
L.M.F., \& Costa, G.M.C. (2015). Conhecimento e fonte de informações de pessoas surdas sobre saúde e doença. Interface (Botucatu), 19(54), 549-60.

Oliveira, Y.C.A., Costa, G.M.C., Coura, A., S., Cartaxo, R.O., \& França, I.S.X. (2012). A língua brasileira de sinais na formação dos profissionais de Enfermagem, Fisioterapia e Odontologia no estado da Paraíba, Brasil. Interface (Botucatu), 16(43), 995-1008.

Oliver-Mora, M., \& Iñiguez-Rueda, L. (2017). El uso de las tecnologías de la información y la comunicación (TIC) en los centros de salud: la visión de los profesionales en Cataluña, España. Interface (Botucatu), 21(63), 945-955.

Omelczuk, F., Fresquet, A., \& Santi, A.M. (2015). Educação, cinema e infância: um olhar sobre práticas de cinema em hospital universitário. Interface (Botucatu), 19(53), 387-94.

Ortega, F., Barros, D., Caliman, L., Itaborahy, C., Junqueira, L., \& Ferreira, C.P. (2010). A ritalina no Brasil: produções, discursos e práticas. Interface (Botucatu), 14(34), 499-512.

Ortega, F., Zorzanelli, R., Meierhoffer, L.K., Kozslowski, L., Rosário, C.A., Almeida, C.F. ... Feldman, C. (2013). A construção do diagnóstico do autismo em uma rede social virtual brasileira. Interface (Botucatu), 17(44), 119-32.

Packer, A.L. (2005). A construção coletiva da Biblioteca Virtual em Saúde. Interface (Botucatu), 9(17), 249-272.

Paixão, P.B.S., Freire, V.P., Lima, M.F.M., Linhares, R.N., Mendonça, A.V.M., \& Sousa, M.F. (2011). A prática de alfabetização em Informação e Comunicação em Saúde: o olhar dos agentes comunitários de Saúde sobre o projeto de Inclusão Digital em Sergipe, Brasil. Interface (Botucatu), 15(38), 937-46.

Passamai, M.P.B, Sampaio, H.A.C., Dias, A.M.I, \& Cabral, L,A. (2012). Letramento funcional em saúde: reflexões e conceitos sobre seu impacto na interação entre usuários, profissionais e sistema de saúde. Interface (Botucatu), 16(41), 301-314.

Pereira, R.C.A., Rivera, U.F.J., \& Artmann, E. (2013). 0 trabalho multiprofissional na estratégia saúde da família: estudo sobre modalidades de equipes. Interface (Botucatu), 17(45), 327-340.
Pessoni, A. (2006). Comunicação para a saúde na América Latina: território de pesquisa interdisciplinar. Comunicação \& Inovação, 7(12), 39-49. https:// doi.org/10.13037/ci.vol7n12.636

Petracci, M. (2012). Comunicação e saúde: um campo variado e pujante. Organicom, 16(17), 40-49.

Pinto, L.O., Oliveira, D.J., \& Duarte, F.M. (2015). Grupo Informativo: estratégia de redução de danos para pessoas apreendidas por consumo/porte de drogas ilícitas. Interface (Botucatu), 19(Supl 1), 965-73.

Pitta, A.M.R., \& Magajewski, F.R.L. (2000). Políticas nacionais de comunicação em tempos de convergência tecnológica: uma aproximação ao caso da Saúde. Interface (Botucatu), 4(7), 61-70.

Pitta, A.M.R., \& Rivera, F.J.U. (2006). Sobre pontos de partida: planejamento em comunicação e integralidade da atenção em saúde. Interface (Botucatu), 10(20), 395-410.

Queiroz, M.V., \& Jorge, M.S. (2006). Estratégias de Educação em Saúde e a qualidade do cuidar e ensinar em Pediatria: a interação, o vínculo e a confiança no discurso dos profissionais. Interface (Botucatu), 10(19), 117-30.

Rabello, E.T., \& Camargo Júnior, K.R. (2012). Propagandas de medicamentos: a saúde como produto de consumo. Interface (Botucatu), 16(41), 557-567.

Ramalho e Oliveira, S.R., Gaspar, D.R., \& Ramalho e Oliveira, G.A. (2009). Uma contribuição da semiótica para a comunicação visual na área da saúde. Interface (Botucatu), 13(29), 409-20.

Ramos-Cerqueira, A.T.A. (1997). A prática pedagógica como processo de comunicação: a relação professoraluno como eixo: o ponto de vista psicológico. Interface (Botucatu), 1(1), 187-192.

Rangel-S, M. L. (2006). Imagens e sentidos no discurso da mídia impressa acerca de uma epidemia de intoxicação acupacional por benzeno. Interface (Botucatu), 10(19), p.92.

Rangel-S, M. L. (2008). Dengue: educação, comunicação e mobilização na perspectiva do controle-propostas inovadoras. Interface (Botucatu), 12(25), 433-41. 
Rasco, J.F.A. (1998). De la acción comunicativa a la sociedad democrática. Interface (Botucatu), 2(3).

Ribeiro, A.C.T. (2000). A natureza do poder: técnica e ação social. Interface (Botucatu), 4(7), 13-24.

Ribeiro, A.C.T. (1998). Tecnologias de informação e comunicação, saúde e vida metropolitana. Interface (Botucatu), 2(2), 7-22.

Rios, C., Ortega, F., Zorzanelli, R., \& Nascimento, L.F. (2015). Da invisibilidade à epidemia: a construção narrativa do autismo na mídia impressa brasileira. Interface (Botucatu), 19(53), 325-336.

Rios, I.C., \& Schraiber, L.B. Uma relação delicada: estudo do encontro professor-aluno. Interface (Botucatu), 2011, 15(36), 39-52.

Rodríguez Zoya, P. (2017). Notas para pensar la complejidad del campo de Comunicación y Salud. En: M. Petracci, P. Schwarz, y P. Rodríguez Zoya. Comunicación y Salud. Las relaciones entre médicos y pacientes en la Modernidad Tardía (pp. 13-68). Buenos Aires: Teseo.

Rogers, E.M. (1996). The field of health communication today:Up-to-date report. Journal of Health Communication, 1(1), 15-23.

Rojas-Rajs, S., \& Soto, E.J. (2013). Comunicación para la salud y estilos de vida saludables: aportes para la reflexión desde la salud colectiva. Interface (Botucatu), 17(46), 587-599.

Romanholi, R.M.Z., \& Cyrino, E.G. (2012). A visita domiciliar na formação de médicos: da concepção ao desafio do fazer. Interface (Botucatu), 16(42), 693-705.

Romanini, M., \& Roso, A. (2014). Midiatização do crack e estigmatização: corpos habitados por histórias e cicatrizes. Interface (Botucatu), 18(49), 363-376.

Rossi, P.S., \& Batista, N.A. (2006). O ensino da comunicação na graduação em Medicina- uma abordagem. Interface (Botucatu), 10(19), 93-102.

Rubim, A.A.C. (2000). A contemporaneidade como idade mídia. Interface (Botucatu), 4(7), 25-36.

Ruiz-Moral, R. (2007). Relación médico-paciente: desafíos para la formación de profesionales de la salud. Interface (Botucatu), 11(23), 619-623.
Ruiz-Moreno, L., Pittamiglio, S.E.L., \& Furusato, M.A. (2008). Lista de discussão como estratégia de ensino-aprendizagem na pós-graduação em Saúde. Interface (Botucatu), 12(27), 883-892.

Sá, M.B., \& Siqueira, V.H.F. (2011). Análise foucaultiana de vídeos educativos para as Ciências da Saúde: ensaiando uma metodologia. Interface (Botucatu), 15(37), 601-12.

Sampaio, A.O. A marca em produtos midiáticos: 0 estudo do posicionamento discursivo aplicado ao telejornalismo. (2011). In: M.F. Ferreira, A.O. Sampaio, \& A. Fausto Neto. Mídia, discurso e sentido. Salvador: Edufba.

Sampaio, J., Santos, G.C., Agostini, M., \& Salvador, A.S. (2014). Limites e potencialidades das rodas de conversa no cuidado em saúde: uma experiência com jovens no sertão pernambucano. Interface (Botucatu), 18 (Supl 2), 1299-1312.

Sanmartino, M., Saavedra, A.A., Gómez i Prat, J., Barba, M.C.P., \& Albajar-Viñas, P. (2015). Não tenham medo de nós: a doença de Chagas segundo os protagonistas. Interface (Botucatu), 19(55), 1063-75.

Santos, A.B.S., Coelho, T.C.B., \& Araújo, E.M. (2013). Identificação racial e a produção da informação em saúde. Interface (Botucatu), 17(45), 341-356.

Santos, A.K., Ribeiro, A.P.G., \& Monteiro, S. (2012). Hanseníase e práticas da comunicação: estudo de recepção de materiais educativos em um serviço de saúde no Rio de Janeiro. Interface (Botucatu), 16(40), 205-218.

Santos, J.E., \& Cardoso, C.M.S. (2011). Narrativas e experiências acerca da loucura: uma reflexão de profissionais de comunicação. Interface (Botucatu), 15(38), 727-39.

Santos, S.N., \& Noro, A. (2013). O uso de filmes como recurso pedagógico no ensino de neurofarmacologia. Interface (Botucatu), 17(46), 705-714.

Sarudiansky, M. (2016). Análisis temático sobre la fibromialgia en la prensa escrita Argentina: descripciones generales y el rol de la psicología. Interface (Botucatu), 20(56), 25-36.

Schraiber, L.B., D'Oliveira, A.F., Hanada, H, Figueiredo, W, Couto, M., Kiss, L., Durand, J., \& Pinho, A. (2003). 
Violência vivida: a dor que não tem nome. Interface (Botucatu), 7(12), 41-54.

Sena, L.M., \& Tesser, C.D. (2017). Violência obstétrica no Brasil e o ciberativismo de mulheres mães: relato de duas experiências. Interface (Botucatu), 21(60), 209-20.

Separavich, M.A., \& Canesqui, A.M. (2012). Análise das narrativas sobre a menopausa de um site brasileiro da internet. Interface (Botucatu), 16(42), 609-22.

Silva, A.F.L., Ribeiro, C.D.M., \& Silva Júnior, A.G. (2013). Pensando extensão universitária como campo de formação em saúde: uma experiência na Universidade Federal Fluminense, Brasil. Interface (Botucatu), 17(45), 371-84.

Silva, L.A.V. (2003). Saúde e produção de sentidos no cotidiano: práticas de mediação e translingüística bakhtiniana. Interface (Botucatu), 7(13), 135-146.

Soares, G.B., \& Caponi, S. (2011). Depressão em pauta: um estudo sobre o discurso da mídia no processo de medicalização da vida. Interface (Botucatu), 15(37), p.437-46.

Soares, R.L. (1998). Aids e imprensa:escritos do jornal Folha de S.Paulo. Interface (Botucatu), 2(2).

Souza, R.A., \& Brandão, E.R. (2012). À sombra do aborto: o debate social sobre a anticoncepção de emergência na mídia impressa brasileira (2005-2009). Interface (Botucatu), 16(40), 161-75.

Stacheski, D.R., \& Massi, G.A.A. (2011). Índices sociais de valor: mass media, linguagem e envelhecimento. Interface (Botucatu), 15(37), 425-36.

Struchiner, M., Ramos, P., \& Serpa Junior, O.D. (2016). Desenvolvimento e implementação de um ambiente virtual de aprendizagem na área da saúde: uma experiência de pesquisa baseada em design. Interface (Botucatu), 20(57), 485-496.

Studart, L., \& Acioli, M.D. (2011). A comunicação da dor: um estudo sobre as narrativas dos impactos da disfunção temporomandibular. Interface (Botucatu), 15(37), 487-503.

Sucupira, A.C. (2007). A importância do ensino da relação médico-paciente e das habilidades de comunicação na formação do profissional de saúde. Interface (Botucatu), 11(23), 624-627.
Tapajós, R. (2007). A comunicação de notícias ruins e a pragmática da comunicação humana: o uso do cinema em atividades de ensino/aprendizagem na educação médica. Interface (Botucatu), 11(21), 165-72.

Teixeira, M.G. (2008). Controle do dengue: importância da articulação de conhecimentos transdisciplinares. Interface (Botucatu), 12(25), 442-51.

Teixeira, R.R. (1997). Modelos comunicacionais e práticas de saúde. Interface (Botucatu), v.1, n. 1.

Teixeira, R.R., Ferigato, S., Lopes, D.M., Matielo, D.C., Sardenberg, M.L., Silva, P. ... Pedroza, R.G. (2016). Apoio em rede: a Rede HumanizaSUS conectando possibilidades no ciberespaço. Interface (Botucatu), 20(57), 337-48.

Teixeira, R.R. (1998). Epidemia e mundo securitário. Interface (Botucatu), 2(2), 77-96.

Terrón, J.L., Leyva, F.M.R., Fernández, S.V., \& Jacobetty, P. (2017). La comunicación en las revistas de salud pública de la biblioteca virtual Scielo. Revista Española de Comunicación en Salud, 8(2), 165-183.

Thiago, C.C., Russo, J.A., \& and Camargo Júnior, K.R. (2016). Hormônios, sexualidade e envelhecimento masculino: um estudo de imagens em websites. Interface (Botucatu), 20(56), 37-50.

Valente, R.G.M. (2011). A comunicação organizacional e as tecnologias de informação e comunicação: um estudo de caso no grupo DST. Tese de doutorado. Universidade do Minho.

Vaz, P., Pombo, M., Fantinato, M., Pecly, G. (2007). O fator de risco na mídia. Interface (Botucatu), 11(21), 145-153.

Ventura, C.A.A., Miwa, M.J., Serapioni, M., \& Jorge, M.S. (2017). Cultura participativa: um processo de construção de cidadania no Brasil. Interface (Botucatu), 21(63), 907-920.

Waisbord, S. (2015). Perspectivas críticas em comunicación y salud: ideas para investigaciones futuras. En: M. Petracci. La salud en la trama comunicacional contemporánea. Buenos Aires: Prometeo.

Xavier, C. Mídia e saúde, saúde na mídia. In: A. Santos. (2006). Caderno mídia e saúde pública. Belo Horizonte: Escola de Saúde Pública/Funed. 
243 // Cyrino et al.

Zago, L.F. (2013). "Armários de vidro" e "corpos-semcabeça" na biossociabilidade gay online. Interface (Botucatu), 17(45), 419-31.

Zucco, L.P., \& Minayo, M.C.S. (2009). Sexualidade feminina em revista(s). Interface (Botucatu), v.13, n.28, p.43-54. 